\title{
Muscular dystrophies and the heart: The emerging role of cardiovascular magnetic resonance imaging
}

\author{
Sophie Mavrogeni MD¹, George Markousis-Mavrogenis MD¹, Antigoni Papavasiliou MD², \\ Elias Gialafos MD³, Stylianos Gatzonis MD ${ }^{4}$, George Papadopoulos MD5, Genovefa Kolovou MD ${ }^{1}$
}

\begin{abstract}
S Mavrogeni, G Markousis-Mavrogenis, A Papavasiliou, et al. Muscular dystrophies and the heart: The emerging role of cardiovascular magnetic resonance imaging. Curr Res Cardiol 2015;2(2):53-62.
\end{abstract}

Muscular dystrophies (MD) constitute a group of inherited disorders, characterized by progressive skeletal muscle weakness and heart involvement. Cardiac disease is common and not necessarily related to the degree of skeletal myopathy; it may be the predominant manifestation with or without any other evidence of muscular disease. Death is usually due to ventricular dysfunction, heart block or malignant arrhythmias. In addition to MD patients, female carriers may present with cardiac involvement. Clinical evaluation, electrocardiography, echocardiography and cardiovascular magnetic resonance imaging (CMR) are the diagnostic tools used for the assessment of these patients. Heart failure in MD may be delayed due to relative physical inactivity. The most common electrocardiographic findings include conduction defects, arrhythmias,

$\mathrm{M}$ uscular dystrophies (MD) constitute a heterogeneous group of inherited disorders characterized by progressive skeletal muscle atrophy and weakness. Diagnosis is based on the severity of muscular disease and type of inheritance, confirmed by genetic assessment.

Cardiac disease is common in MD and is not necessarily related to the severity of skeletal myopathic disease; on the contrary, heart involvement may be the presenting or predominant manifestation of MD in some cases, without any other evidence of muscular disease. Cardiac death in these patients is usually due to ventricular dysfunction, heart block and/or malignant arrhythmias. Recently, increased survival rates due to better management of lung disease have emphasized the role of heart disease as an important contributor to the mortality of MD (1). Cardioprotective medical treatment may delay the development of heart disease; therefore, early diagnosis is essential for MD patients' survival (2-6). Clinical evaluation, electrocardiography (ECG) and echocardiography are the classic screening tools $(7,8)$; cardiovascular magnetic resonance imaging (CMR) may be of considerable value for early detection of cardiac disease - which may remain silent for long periods - due to its capability to characterize tissue $(9,10)$.

\section{SKELETAL MUSCLE DISEASES COMMONLY ASSOCIATED WITH CARDIAC INVOLVEMENT}

Dystrophin-associated diseases (dystrophinopathies)

Dystrophinopathies include Duchenne muscular dystrophy (DMD), Becker muscular dystrophy (BMD), X-linked dilated cardiomyopathy hypertrophy and, potentially, evidence of myocardial necrosis, depending on the type of MD. Echocardiography is a routine technique used to assess left ventricular dysfunction, independent of age of onset or mutation. In some cases, it can also identify early, silent cardiac dysfunction. CMR is the best technique for accurate and reproducible quantification of ventricular volumes, mass and ejection fraction. CMR has documented a pattern of epicardial fibrosis in both dystrophinopathy patients and mutation carriers that can be observed even if overt muscular disease is absent. Recently, CMR techniques, such as postcontrast myocardial T1 mapping, have been used in Duchenne muscular dystrophy to detect diffuse myocardial fibrosis. A combined approach using clinical assessment and CMR evaluation may motivate early cardioprotective treatment in both patients and asymptomatic carriers, and prevent the development of serious cardiac complications.

Key Words: Cardiovascular magnetic resonance imaging; Heart failure; Muscular dystrophies

(XLCM) and facioscapulohumeral muscular dystrophy (FSHD). DMD and BMD are X-linked disorders affecting the synthesis of dystrophin, a large sarcolemmal protein that is absent in DMD (11), and reduced in amount or abnormal in BMD (12). The incidence of DMD is one in 3500 male newborns with a prevalence of six in 100,000 males (13). DMD is characterized by weakness of the leg, pelvic and shoulder girdle muscles starting in early childhood. DMD and BMD account for $>80 \%$ of all causes of MD.

Dystrophin provides the connection between a large complex of glycoproteins in the muscle cell membrane (called the dystrophinglycoprotein complex) and intracellular actin filaments, transmitting forces generated by sarcomere contraction to the extracellular matrix $(14,15)$. Absence, reduced levels or abnormal structure of dystrophin leads to membrane fragility, making muscle fibres prone to injury during contraction (16). As muscle disease progresses, muscle repair cannot adequately compensate for damage, leading to necrosis of skeletal and cardiac myocytes and progressive replacement by fibrofatty tissue (17).

BMD is a milder variant of dystrophinopathy with a better prognosis. Incidence of BMD is one in 18,450 males and prevalence is 2.4 per 100,000 in the general population $(11,18)$. The first symptoms appear between three and 21 years of age, with a mean age of onset of 11 years. The age at death is 21 to 89 years (mean age approximately 45 years) (19-22).

XLCM is a primary myocardial dystrophinopathy, presenting as congestive heart failure in teenage males, with almost no skeletal muscle disease. It is characterized by rapid progression, leading to

${ }^{1}$ Onassis Cardiac Surgery Center; ${ }^{2}$ Pentelis Children Hospital; ${ }^{3}$ First Department of Neurology, University of Athens; ${ }^{4}$ Department of Neurosurgery,

Evangelismos Hospital, Athens Medical School; ${ }^{5}$ Agia Sophia Children's Hospital, Athens, Greece

Correspondence: Dr Sophie Mavrogeni, 50 Esperou Street, 175-61 P.Faliro, Athens, Greece. Telephonelfax 30-210-98-82-797, e-mail soma13@otenet.gr 
cardiac death within one to two years. The distinction between XLCM and BMD with mild skeletal muscle weakness is difficult. Therefore, these entities are considered to be part of the same disease expression (23).

FSHD is the third most common MD (after DMD and myotonic dystrophy), with an estimated prevalence of one per 20,000 in the adult European population (24).

\section{Cardiac disease in dystrophinopathies}

After the third decade of life, the majority of DMD patients have established cardiomyopathy (25). Although clinically overt heart failure may be delayed or absent due to relative physical inactivity, cardiomyopathy is the leading cause of death in DMD and myocardial damage precedes decline in left ventricular (LV) systolic function. Neither the age of onset nor the severity of cardiomyopathy is correlated with the type of mutation (26). It was recently documented that in DMD with preserved ejection fraction, the addition of eplerenone to background angiotensin-converting enzyme inhibitors or angiotensin II receptor blockers attenuates the progressive decline in LV systolic function (27).

Cardiomyopathy is the main clinical complication in patients affected by subclinical or mild BMD. The clinical presentation is usually characterized by early right ventricular dysfunction and is later associated with LV impairment. In mild BMD, myocardial damage may develop because the patients, who are unaware of a possible cardiac disease, can still perform strenuous muscle exercise and, through pressure or volume overload, may induce mechanical stress, which is harmful for dystrophin-deficient myocardial cells (28).

\section{Cardiac involvement in female carriers of dystrophinopathies}

Cardiac disease in female carriers of dystrophinopathies may present as hypertrophy, arrhythmias or dilated cardiomyopathy (29). The percentage of patients with clinically overt cardiac involvement increases significantly with age, from $15 \%$ in carriers $<16$ years of age to $45 \%$ in carriers $\geq 16$ years of age. In contrast, significant cardiac disease is unlikely in female carriers $<16$ years of age (30). In a crosssectional study involving $85 \mathrm{DMD}$ and $44 \mathrm{BMD}$ carriers 18 to 58 years of age, LV dilation and dilated cardiomyopathy were observed in $18 \%$ and $8 \%$, respectively (31). ECG abnormalities were found in only $47 \%$ of this population (32). Another series of 56 adult female carriers did not present any ECG abnormalities, but ventricular dilation or hypertrophy was documented in $14 \%$ and dilated cardiomyopathy in $7 \%(33)$. Nevertheless, severe heart failure may develop in some women, necessitating heart transplantation $(29,34,35)$. Exercise may unmask LV systolic dysfunction in female carriers (36). In a study conducted by our group, CMR revealed myocardial fibrosis in the majority of DMD and BMD mother-carriers, although the clinical presentation and the usual noninvasive assessment were mildly abnormal (37). Therefore, detailed cardiac evaluation, at least once after the teenage years, should be recommended for all female carriers to enable an early start of cardiac treatment (38). XLCM female carriers have later onset, typically during the fifth decade of life, and slow progression of heart failure (39).

\section{Emery-Dreifuss MD}

Emery-Dreifuss MD (EDMD) is characterized by early contractures of the elbows, Achilles tendons (toe walking), posterior cervical muscles (rigid spine) and muscle weakness in a humeroperoneal distribution. Joint contractures occur early, typically before the development of any significant weakness. EDMD can be X-linked or autosomal; X-linked recessive EDMD (EDMD1) has a prevalence of one in 100,000 males. EDMD1 is caused by various mutations in the STA gene (40). The protein product (emerin) is a member of a protein complex that links filamentous actin in the cytoskeleton to the nuclear lamina and/or chromatin (41,42). Autosomal dominant EDMD (EDMD2) and a rare autosomal recessive form of EDMD are caused by a mutation in the lamin A/C gene $(43,44)$ with unknown prevalence. Lamin A/C codes for alternatively spliced lamins A and C. Additionally, lamin $\mathrm{A} / \mathrm{C}$ mutations can cause several other phenotypes, including limb-girdle MD (LGMD) type 1B, autosomal dominant dilated cardiomyopathy with conduction defects (CMD1A), autosomal-recessive EDMD, autosomal-recessive axonal neuropathy, familial partial lipodystrophy, mandibuloacral dysplasia and progeria syndromes, all referred to as laminopathies.

\section{Cardiac disease in EDMD}

In EDMD1, the most common cardiac finding is conduction disturbances (45). LV dysfunction and atrial paralysis can also be observed $(46,47)$. Sudden death is common and highly unpredictable $(48,49)$; therefore, pacemakers are often needed at 30 years of age (range 14 to 44 years) (50-53). Heart failure and atrial or ventricular arrhythmias occur only in a minority of patients; however, the risk may increase as patients with a pacemaker survive longer $(47,49)$.

\section{Cardiac involvement in female carriers of EDMD}

Female carriers of an emerin mutation have no muscular symptoms, although some may be at risk for cardiac arrhythmias and sudden death (52-55); however, studies investigating cardiac involvement in EDMD1 carriers are not available.

\section{LGMD}

LGMD consist of a heterogeneous group of MD with involvement of pelvic and shoulder girdle musculature (55). Seven autosomal dominant (LGMD1A to LGMD1G) and 14 autosomal-recessive forms (LGMD2A to LGMD2 M) have been already recognized as genes responsible for LGMD. LGMD type 2A is caused by mutations in the calpain 3 gene (CAPN3) and complete lack of functional CAPN3 leads to the most severe muscle wasting. CAPN3 is suggested to be involved in maturation of contractile elements after muscle degeneration (55).

The disease course of autosomal dominant LGMD is usually relatively mild and the age of onset ranges from childhood to the fourth decade of life (56). The clinical presentation of autosomal-recessive LGMD is more severe and resembles that of dystrophinopathies (56). The prevalence of all forms of LGMD ranges from one in 23,000 to one in 150,000 (2,56). Disruption of proteins that mediate sarcolemmal repair or other cell-signalling pathways and defective enzymes can result in the limb-girdle dystrophic phenotype (57); however, the exact functional role of the affected proteins and the precise pathogenic mechanism leading to LGMD remains unknown.

\section{Cardiac disease in LGMD}

LGMD1: Cardiomyopathy was reported in allelic disorders with mutations in myotilin (myofibrillar myopathies) and caveolin-3 (autosomal dominant rippling muscle disease), which may overlap with LGMD1A and C, respectively. LGMD1E has been reported in only one family (58). The phenotype is similar to LGMD1B. Dilated cardiomyopathy with conduction defects and/or adult-onset LGMD and sudden death, despite pacemaker therapy, has been described (58). LGMD2C, 2D, 2E and 2F: These types of LGMD are caused by mutations in the transmembrane proteins of the sarcoglycan complex. The prevalence of sarcoglycanopathies is approximately one in 178,000 (59). LGM2D is the most frequent sarcoglycanopathy, followed by LGMD2E andLGMD2C, while LGMD2F is the least common (59-61). Disease severity is related to the percentage of residual sarcoglycan protein. Mild ECG and/or echocardiographic changes occur in $20 \%$ to $30 \%$ of sarcoglycanopathy $(62,63)$. The risk for cardiac involvement is low in LGMD2D; however, dilated cardiomyopathy and ventricular arrhythmias may occur in LGMD2E with severe DMD-like dystrophy (64,65). Although a correlation between genotype/phenotype and prognosis has not yet been established, detailed evaluation of sarcoglycanopathies for cardiac disease is necessary (66). 
LGMD2I: LGMD2I is caused by mutations in the fukutin-related protein (FKRP) gene (67). Mutant FKRP directly or indirectly disturbs glycosylation of the transmembrane protein a-dystroglycan in muscle cells. Appropriate glycosylation is necessary for a-dystroglycan to bind components of the extracellular matrix, including laminin-2 (68).

Cardiac involvement has been reported in $29 \%$ to $62 \%$ of patients with LGMD2I (69-73). LV wall motion changes and dilated cardiomyopathy may begin as early as the teenage years. A significant percentage of patients may develop symptomatic heart failure over time, beginning at a mean age of 38 years (range 18 to 58 years) (70); this is not always associated with severe muscle weakness $(67,70)$. LGMD2I patients are also at risk for respiratory impairment and may require nocturnal ventilation $(69,70)$.

\section{Myotonic dystrophy}

Myotonic dystrophy type 1 (DM1) is an autosomal-dominant muscular dystrophy caused by expansion of cytosine-thymine-guanine (CTG) trinucleotide repeats in the myotonic dystrophy protein kinase (DMPK) gene. DM1 is the most common MD in adults. It has a prevalence of 2.1 to 14.3 per 100,000 worldwide, although its prevalence is higher in certain populations due to genetic isolation (74). Muscle involvement is characterized by myotonia and weakness of the facial, sternocleidomastoid and distal muscles, combined with systemic manifestations including cataract, gastrointestinal, central nervous system and cardiac abnormalities. Based on age at onset and symptoms, four clinical categories have been distinguished: congenital; childhood; classical (adultonset); and mild (late-onset) type (75). Life expectancy is reduced in DM1, mainly in those with early disease onset and proximal muscle(s) involvement (76). Median survival is 59 to 60 years for patients with adult onset and 35 years for patients with the congenital type (77). Progressive respiratory failure remains the leading cause of mortality, followed by cardiac death in $20 \%$ to $30 \%$ of cases (76-78).

\section{Cardiac disease in DM1}

Cardiac abnormalities can be diagnosed as early as the second decade of life in the childhood type (79). Conduction disturbances occur in $65 \%$ of adults (80); pathology studies showed fibrosis of conduction system and diffuse interstitial fibrosis throughout the myocardium (81). Ventricular dysfunction and structural changes have been documented by both echocardiography and cardiovascular magnetic resonance imaging $(82,83)$. However, the prevalence of heart failure is approximately $2 \%$ to $7 \%(83,84)$.

Sudden death is not unusual in DM1, and was initially believed to be due to conduction disturbances. However, reports of sudden death in patients with pacemakers and episodes of sudden death related to well-documented ventricular tachycardia (VT) suggested that VT may be a more frequent cause of sudden death than it was previously believed $(78,85)$; therefore, prophylactic implantable cardioverterdefibrillator (ICD) implantation should be carefully evaluated in the high risk for sudden death patients with good prognosis of their neuromuscular disease.

\section{Myotonic dystrophy type 2}

Myotonic dystrophy type 2 (DM2) is an autosomal dominant disorder resembling adult-onset DM1, but with more favourable prognosis compared with DM1. Three classes of large non-DM2 repeat alleles were identified: up to (CCTG)-24 with two interruptions; up to (CCTG)-32 with up to four interruptions; and uninterrupted (CCTG)-22-33. Large non-DM2 alleles were more common in African Americans than in European Caucasians. Uninterrupted alleles were significantly less stable than interrupted alleles (86).

Patients present with predominantly proximal lower limb weakness or weakness of deep finger flexors $(86,87)$. A review of 209 DM2 patients reported that first symptoms occurred between 13 and 67 years of age (median age at onset 48 years) (86). Facial muscle weakness is less severe, myotonia is typically less apparent and muscle atrophy is milder than in DM1. Muscle pain is a major complaint of DM2 and systemic manifestations such as cataract, cardiac and endocrine dysfunction may also coexist. However, in contrast to DM1, respiratory failure is rather unusual $(86,87)$.

\section{Myofibrillar myopathies}

Myofibrillar myopathies (MFM) represent a group of genetically disorders, associated with peripheral neuropathy and cardiac disease. MFM present in adult life with slowly progressive muscular weakness.

Desmin-related MFM (desminopathies) may have various phenotypes depending on the type of mutations. Heart disease may precede, coincide with or succeed skeletal disease. Conduction disturbances and arrhythmias are frequent in desminopathies because desmin is an important component of Purkinje fibres (88).

Mutations in a-B crystallin may also cause phenotypic features of desminopathy. Patients with a-B crystallinopathy may develop hypertrophic cardiomyopathy $(89,90)$ and mutation in BAG3 may cause severe childhood MD with cardiomyopathy and respiratory failure (91).

\section{Other MD}

Mild to moderate cardiomyopathy was detected in one of three affected family members with late-onset autosomal dominant distal myopathy (92). Several rare X-linked myopathies are also associated with cardiomyopathy. X-linked vacuolar cardiomyopathy and myopathy (Danon disease) is caused by mutations in the gene encoding lysosome-associated membrane protein-2 (LAMP-2) at Xq24 (93) and cardiac disease is the dominant clinical feature. Skeletal muscle involvement is usually mild, and is observed in $90 \%$ of male patients and $33 \%$ of female relatives.

A study involving 20 men and 18 women with genetically confirmed Danon disease reported cardiomyopathy in all patients (94). Men were severely affected before 20 years of age. The most frequent findings were hypertrophic cardiomyopathy with impaired LV function and Wolff-Parkinson-White syndrome. Most affected women developed dilated cardiomyopathy in adulthood. The mean age at death was 19 years in male and 40 years in female patients (94).

Barth syndrome, an X-linked disorder in infancy, characterized by cardiomyopathy, neutropenia, skeletal myopathy and growth delay, is caused by mutations in the taffazin gene at Xq28 that result in cardiolipin deficiency and abnormal mitochondria (92). Female carriers appear to be healthy. In a study involving 34 men, 90\% had dilated cardiomyopathy, $53 \%$ had prominent LV trabeculations and ventricular arrhythmias were frequent in adolescents (95).

McLeod syndrome is a late-onset X-linked disorder caused by mutations of XK, a gene of unknown function, and characterized by movement disorders (chorea), cognitive impairment, myopathy and acantocytosis. A few cases of female mutation carriers have been reported (96). Approximately $65 \%$ of individuals develop cardiac disease, including dilated cardiomyopathy, atrial fibrillation and tachyarrhythmia (96).

Mutations in the four-and-a-half LIM domain gene (FHL1) have been identified as causative for reducing body myopathy, X-linked scapuloperoneal myopathy and X-linked myopathy with postural muscle atrophy (XMPMA). FHL1 is highly expressed in skeletal and cardiac muscle. Hypertrophic cardiomyopathy was observed in four of nine XMPMA patients, and dilated cardiomyopathy in one of 11 reducing body myopathy patients $(97,98)$; however, respiratory failure remains the major cause of death.

An early-onset myopathy with fatal cardiomyopathy, due to homozygous C-terminal TTN deletions, has been described as the only titinopathy involving both heart and skeletal muscle (99).

Mutations in the beta-cardiac myosin heavy chain gene (MYH7) may cause various phenotypes ranging from pure peripheral muscle disease to isolated cardiomyopathies. However, MYH7 mutations combining symptomatic distal myopathy and cardiac involvement have been reported $(100,101)$. 


\section{CURRENTLY USED TECHNIQUES FOR THE EVALUATION OF HEART INVOLVEMENT IN MD ECG}

The most common electrocardiographic findings in MD include conduction disease (PR interval $\geq 210 \mathrm{~ms}$, QRS duration $\geq 120 \mathrm{~ms}$, left anterior or posterior fascicular hemiblock), arrhythmias (supraventricular or ventricular), hypertrophy (Sokolow-Lyon index $\geq 35 \mathrm{~mm}$ ) and evidence of myocardial necrosis, depending on the type of MD.

$\mathrm{DMD}$, the most common and severe form of childhood MD, is associated with increased R/S ratio in the right precordial leads, deep $Q$ waves in the lateral leads, conduction abnormalities and arrhythmias (mainly supraventricular but also ventricular). In a study involving 131 individuals with DMD, ECG was abnormal in 78.6\%. All were in sinus rhythm and the following percentages were found for the main variables studied: short PR interval, $18.3 \%$; abnormal $\mathrm{R}$ waves in V1, 29.7\%; abnormal Q waves in V6, 21.3\%; abnormal ventricular repolarization, $54.9 \%$; abnormal QS waves in inferior and/or upper lateral wall, 37.4\%; conduction disturbances in right bundle branch, 55.7\%; prolonged QT, 35.8\%; and wide QRS, 23.6\% (102). The prevalence of incomplete right bundle branch block was significantly higher in patients with FSHD (33\% [95\% CI 22.6\% to 44\%]) than in the normal population (1.2\% to $3.4 \%)$ (103). Additionally, the prevalence of complete right bundle branch block in FSHD (3.8\% [95\% CI $-0.4 \%$ to $8.4 \%]$ ) tended to be higher than in the normal population $(0.16 \%$ to $0.8 \%)$ (104).

In EDMD, normal myocardium is gradually replaced by fibrous and adipose tissue; this process usually starts in the atria (leading to atrial arrhythmias) or involves the atrioventricular node, leading to conduction abnormalities, sometimes requiring a pacemaker, and finally the ventricles, causing progressive dilation and systolic function failure (105). Sudden death may be the presenting symptom of EDMD; therefore, cardiac screening of relatives, including female carriers with $\mathrm{X}$-linked EDMD, is recommended (106).

Patients with mutations in the lamin A/C gene (1p1-q21 locus) develop sinus and atrioventricular node dysfunction, ventricular arrhythmias and adult-onset cardiomyopathy with mild skeletal myopathy. The inheritance pattern is autosomal dominant with high penetrance, and patients are at high risk for sudden death (107).

Atrioventricular and intraventricular conduction defects are common in both DM1 and DM2, with infrahisian block being an important cause of sudden death (103). Additionally, cardiac arrhythmias may occur early during the course of the disease, even in the absence of severe neuromuscular impairment. In a population of 31 DM1 patients, $38 \%$ had first-degree atrioventricular block (AVB) and $51 \%$ had intraventricular conduction disturbances $(62 \%$ had late potentials) (108).

Not only ECG but also Holter monitoring is necessary for evaluation of MD patients. Cardiac surveillance, including routine monitoring of electrocardiograms, may detect early DCM development in both DMD and BMD (109). In addition, in 32\% of MD1 patients with a normal ECG, the $24 \mathrm{~h}$ Holter monitoring showed arrhythmias and conduction abnormalities (110). In MD1, Holter monitoring should be performed on a regular basis, at intervals not $>6$ months (111).

In a study involving MD1 patients including ECG, Holter and echocardiography, a normal ECG was not associated with normal Holter and echo (113). In another study investigating MD1 using Holter, atrial fibrillation (AF) and atrial flutter (AFL) were frequent in MD1 and lead to increased mortality. AFL could present as $1 / 1$ AFL with a poor tolerance and a risk for misdiagnosis despite frequent conduction disturbances. Another study including 104 DM2 and 117 DM1 patients who underwent baseline and follow-up assessments of ECG, 24 h Holter monitoring, two-dimensional echocardiography and electrophysiological studies, showed that $10 \%$ of DM2 patients versus $31 \%$ of DM1 patients had PR $\geq 200 \mathrm{~ms}$ and $17 \%$ of DM2 patients versus $48 \%$ of DM1 patients had QRSD $\geq 100$ ms. Six patients with DM2 versus 28 patients with DM1 required PM/ICD implantations (114). Holter recording has been used not only for accurate diagnosis of heart rhythm in MD, but also for treatment evaluation (115-118).

\section{Echocardiography}

Echocardiography is the most commonly used imaging technique for LV evaluation and has already assessed marked variability in the severity of LV dysfunction in DMD, independently of age of onset or mutation groups (119).

In another study, echocardiograghy identified LV systolic dysfunction in $20.6 \%$ and reduced global longitudinal strain in $21.7 \%$ of MD1 patients (120). An echocardiographic study involving sarcoglycanopathy patients detected dilated cardiomyopathy in $17 \%$ (121). Echocardiography also assessed a high prevalence of LV dysfunction in DMD, with frequent evidence of systolic ventricular asynchrony, particularly in patients with ejection fraction $<35 \%$ (122). LV dysfunction with reduced LV ejection fraction has been already observed in EDMD (123). Echocardiography also revealed cardiac involvement in $24 \%$ of patients with LGMD2A-I (124). In a multicentre retrospective analysis of 38 patients with LGMD 2I, 55.3\% had cardiac abnormalities, of whom $24 \%$ had heart failure. Heterozygotes for the common C826A mutation developed cardiac disease earlier than homozygotes. All patients initially improved, while receiving standard therapy. No correlation between skeletal muscle disease, cardiomyopathy and/or respiratory insufficiency was identified (125). Structural heart disease is also frequent in myotonic dystrophy, with LV dilation or hypertrophy observed in approximately $20 \%$ and LV systolic dysfunction in $14 \%$ of patients (126). Clinically overt heart failure, however, was documented in only $2 \%$, according to the same report. In a study evaluating diastolic heart function in MD1 using echocardiography, an increase of the left atrial diameter and mitral deceleration time suggesting diastolic abnormalities was identified (127). In cases with a suboptimal acoustic window, three-dimensional echocardiography can serve as an excellent alternative (128).

In a recent case report, the abnormal region identified by voltage mapping was concordant with the segmental impairment in twodimensional strain pattern detected by speckle tracking; this is promising for the application of this technique in the evaluation of MD1 (129). In DM2, although muscular disease is less prominent, cardiac involvement may be developed; therefore, cardiac evaluation is recommended to identify those at high risk for potential major cardiac events (130).

Finally, echocardiography using transmural strain profile can detect subclinical LV dysfunction in patients with DMD without wall motion abnormalities by conventional echocardiography (131). The application of myocardial strain imaging in DMD patients was characterized by decreased peak systolic strain of the posterior wall, despite normal standard echocardiographic findings (132). These studies, although very promising, were not universally accepted for the routine assessment of MD.

\section{Why CMR in MD?}

CMR is a noninvasive, nonradiating technique ideal for serial evaluation of cardiac volumes, mass, ejection fraction, inflammation and fibrosis because it is operator independent and has excellent reproducibility (133). Early indexes, such as strain analysis, may be abnormal in MD before any cardiac dysfunction is detected. CMR tagging showed that DMD patients exhibit abnormal global and segmental circumferential strain compared with age- and sexmatched controls, despite similar LV volumes and ejection fractions (134). Similar findings showed that abnormal myocardial strain precedes both the age-dependent decrease in ejection fraction and the development of myocardial fibrosis in DMD (134). Finally, strain analysis is more sensitive to detect serial impairment in LV function compared with LV ejection fraction (135); therefore, it is of great value to assess treatment efficacy. These indexes, although promising, are not widely accepted and do not represent a robust tool for detection of cardiac involvement in MD. 


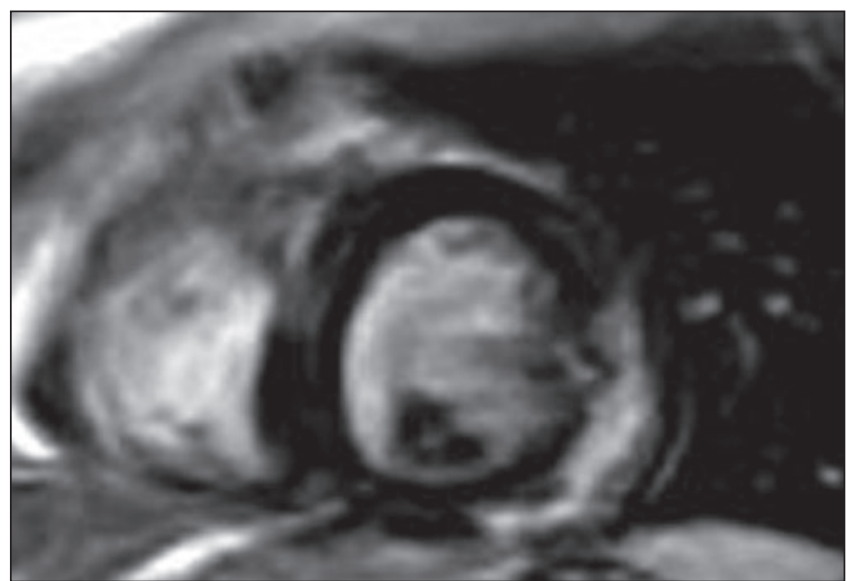

Figure 1) Late gadolinium enhancement in the lateral wall of the left ventricle in a patient with Becker muscular dystrophy

In contrast, the most robust CMR data are referring to early myocardial fibrosis in DMD, BMD and female carriers, detected by late gadolinium enhancement (LGE). The pathology of cardiomyopathy in dystrophinopathies includes the presence of subepicardial fibrosis in the inferolateral wall $(136,37)$, similar to that observed in viral myocarditis. The application of CMR in MD, in addition to the standard monitoring by echocardiography and ECG, is of great value because early initiation of heart failure treatment may delay the progression of LV dysfunction and/or even reverse cardiac remodelling in X-linked dystrophinopathies (137); and because myocardial fibrosis, assessed by LGE, may be observed, even if echocardiographic evaluation is still normal $(136,138)$ and CMR may serve as an early sensitive index to motivate the start of cardioprotective treatment. It may also be applied as a screening tool to identify patients at risk for ventricular arrhythmias, more advanced disease, adverse LV remodelling and death (139) (Figure 1). Finally, in mutation carriers, CMR revealed a pattern of fibrosis similar to that observed in DMD (37) (Figure 2), even in the absence of overt muscular disease. Recently, CMR techniques, such as postcontrast myocardial T1 mapping, have been applied in DMD to detect diffuse myocardial fibrosis (140).

In EDMD, CMR data are limited due to the rarity of the disease and the frequent pacemaker implantation in this population. Comparative studies using echo and CMR in EDMD showed absence of myocardial fibrosis, despite the presence of more subtle myocardial abnormalities, including a decrease in systolic circumferential strain in the inferior segment, suggesting a different pathophysiology of cardiac disease in EDMD compared with DMD/BMD, where fibrosis usually precedes systolic dysfunction (141).

Heart involvement in LGMD using CMR demonstrated subepicardial pattern of LGE similar to that detected in BMD, suggesting that this damage represents a nonspecific pattern due to increased mechanical stress in this area (142). However, LGMD2I and LGMD2B usually lead to mild structural and functional cardiac abnormalities, although severe dilated cardiomyopathy may also occur (143). Another study that evaluated LGMD2I using physical examination, echocardiography, resting and $24 \mathrm{~h}$ ambulatory ECG and CMR proved that both the gene mutation and the severity of the muscle disease were not predictive of cardiac involvement; on the contrary, CMR documented a high prevalence of myocardial functional abnormalities, fatty replacement and fibrosis. Reduced contractility and CMR abnormalities were highly prevalent in LGMD2I, suggesting that all patients should be referred for cardiac evaluation $(144,145)$.

Structural alterations of the myocardium, such as fibrosis and fatty infiltration, were also observed in autopsy studies of patients

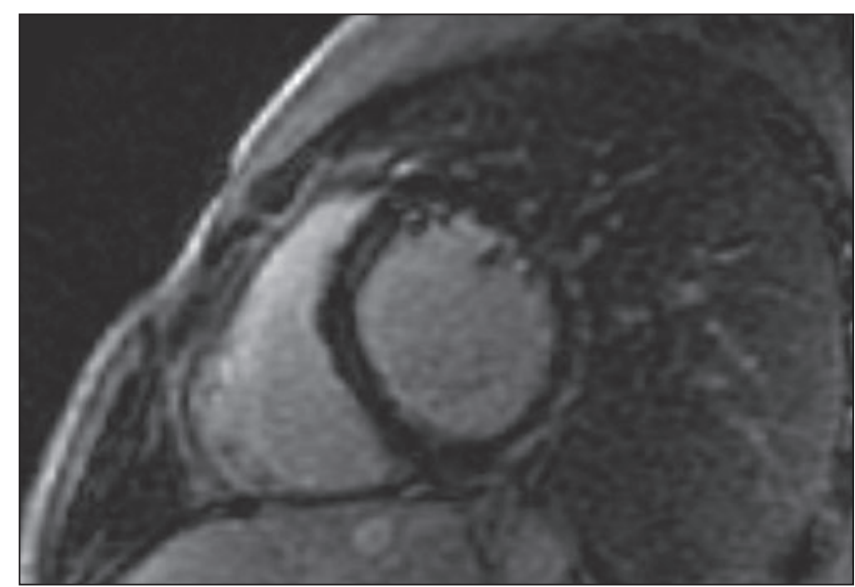

Figure 2) Late gadolinium enhancement in the lateral wall of the left ventricle in a female carrier of Duchenne muscular dystrophy

with myotonic dystrophy. CMR evaluation of these patients revealed functional and structural abnormalities in $44 \%$ and myocardial fibrosis in $12.5 \%$ (146). Patients with myotonic dystrophy may present with cardiomyopathy, which is usually more benign in DM2 compared with DM1. CMR can define the LV abnormalities of the disease, such as dilation, systolic dysfunction, hypertrophy and, occasionally, noncompaction $(147,148)$; however, typical LGE patterns have not been observed in this population.

What type of sequences should be included in the CMR evaluation of MD?

CMR, using cine sequences, can measure ventricular volumes and ejection fraction without contrast agent and provides threedimensional images of the heart, also feasible with three-dimensional echocardiography. CMR ejection fraction and volumes are more accurate and reproducible than other imaging techniques; however, there is a good correlation between CMR and other techniques (132). Echocardiography is still the everyday bedside tool, but CMR is ideal for the serial evaluation of ventricular volumes, mass and function due to its high reproducibility (132).

CMR is the most reliable imaging technique to detect and quantify scar or fibrotic tissue (viability study). Fibrotic/scar lesions retain contrast agent and, therefore, appear bright (149). The preferred imaging time for scar detection is between $10 \mathrm{~min}$ and $20 \mathrm{~min}$ after contrast agent administration, when the differences between scar tissue, normal myocardium and the blood pool are maximal. This method is referred as LGE CMR and is the gold standard for the in vivo assessment of myocardial scar. CMR can detect scar tissue in as little as $1 \mathrm{~cm}^{3}$ of tissue, substantially less than other in vivo methods, and has shown excellent agreement with histology (149). Not only the presence, but also the LGE amount plays an important role in patients' prognosis, because even a small area of LGE $(<2 \%$ of LV mass) was associated with a $>7$-fold increase in risk for a major adverse cardiac event in patients with coronary artery disease (150). Many studies have documented the presence of myocardial scar in both MD and carriers, emphasizing its role as an early strong diagnostic sign of heart involvement and as a motivating factor for early start of cardiovascular treatment $(37,136)$. A recent CMR evaluation of patients with nonischemic cardiomyopathy documented that LGE was a powerful and independent predictor of malignant arrhythmic prognosis, while its amount and distribution did not provide additional prognostic value; therefore, it may contribute to identify candidates for ICD therapy not fulfilling the current criteria based on LV ejection fraction (151).

Myocarditis can present in MD under different clinical scenarios (varying from severe hemodynamic collapse to subclinical disease), is 
undetectable by blood inflammatory indexes and may lead to dilated cardiomyopathy. MD patients are more prone to myocarditis compared with the rest of population because abnormal dystrophin acts as a vehicle for different viruses $(152,153)$. During the early stages, it may remain undetected by echocardiography, which is unable to distinguish tissue structural changes, occurring without associated changes in LV ejection fraction, while an increase in cardiac troponin was found in only $20 \%$ of cases (154). Additionally, according to American College of Cardiology/American Heart Association guidelines, myocardial biopsy should be used only for patients with unexplained newonset heart failure $<2$ weeks in duration associated with a normal-sized or dilated LV with hemodynamic compromise and should not be used for screening or follow-up (138); it is limited by sampling error and observer expertise (155).

CMR diagnoses myocarditis using three types of images: T2-weighted (T2-W), early T1- weighted images taken 1 min after injection of the contrast agent (EGE), and delayed enhanced images (or LGE). T2-W is an indicator of tissue water content, which is increased in inflammation or necrosis, such as myocarditis and myocardial infarction. To enhance the detection of pathology on CMR, images should be obtained early and late after gadolinium injection. Higher levels of EGE are due to increased membrane permeability or capillary blood flow. LGE represent the amount of scar tissue. A combined CMR approach using T2-W, EGE and LGE has a sensitivity of $76 \%$, a specificity of $95.5 \%$ and a diagnostic accuracy of $85 \%$ for the detection of myocarditis (156). Myocarditis, missed by other noninvasive techniques, has been already described in DM using CMR, which may have significant implications in patients' treatment, risk stratification and prognosis (153).

Fat deposits are often found around the heart. Epicardial fat is the adipose tissue accumulated between the visceral pericardium and the myocardium; it has a variable distribution, being more prominent in the atrioventricular, interventricular grooves and right ventricular free wall, and is nourished by the coronary arteries (157). CMR is the technique of choice for fat quantification (157). In a small case series, histological studies of hearts from DMD patients on autopsy identified fat infiltration (158).

Finally, CMR has the capability to characterize myocardial tissue using $\mathrm{T}_{1}$ mapping techniques. Patients with MD diseases are at risk for heart failure due to diffuse myocardial fibrosis and LV remodelling. Because native $\mathrm{T} 1$ values are raised in the presence of diffuse fibrosis and edema, T1 mapping by CMR is emerging as a potential tool to assess diffuse myocardial involvement. Native T1 values are increased in DMD and may serve as early markers of diffuse fibrosis (159).

\section{Limitations of CMR}

- Lack of availability and expertise;

- Difficulties in collaboration between cardiologists and radiologists, regarding the interpretation and clinical significance of CMR findings;

- Ignorance of neurologists regarding the diagnostic and prognostic information, offered by CMR; and

- High cost of examination.

\section{CONCLUSIONS}

Cardiac involvement is common in both MD patients and carriers. Currently used noninvasive techniques are low cost, widely available and do not require high expertise. However, they cannot identify the preclinical cardiac involvement in MD patients and carriers.

Due to its capability to detect myocardial changes before they will be clinically overt, CMR is the technique of choice for early, accurate diagnosis, treatment and follow-up of MD patients and carriers. However, further multicentre studies are needed before CMR will be included in the routine algorithm of MD patients and carriers.

\section{HIGHLIGHTS}

- Cardiac disease is common in MD and is not related to skeletal myopathy.

- High R/S in the right precordial and deep Q in the lateral leads are typical in DMD.

- Conduction defects are an important cause of sudden death in EDMD, DM1 and DM2.

- Fibrosis is an early finding in carriers and patients, even if echo is normal.

- CMR serves as sensitive index to early start cardioprotective treatment.

\section{REFERENCES}

1. Hermans MC, Pinto YM, Merkies IS, de Die-Smulders CE, Crijns HJ, Faber CG. Hereditary muscular dystrophies and the heart.Neuromuscul Disord 2010;20:479-92.

2. Duboc D, Meune C, Lerebours G, Devaux JY, Vaksmann G, Becane HM. Effect of perindopril on the onset and progression of left ventricular dysfunction in Duchenne muscular dystrophy. J Am Coll Cardiol 2005;45:855-7.

3. Ishikawa Y, Bach JR, Minami R. Cardioprotection for Duchenne's muscular dystrophy. Am Heart J 1999;137:895-902.

4. Jefferies JL, Eidem BW, Belmont JW, et al. Genetic predictors and remodeling of dilated cardiomyopathy in muscular dystrophy. Circulation 2005;112:2799-804.

5. Kajimoto H, Ishigaki K, Okumura K, et al. Beta-blocker therapy for cardiac dysfunction in patients with muscular dystrophy. Circ J 2006;70:991-4.

6. Ramaciotti C, Heistein LC, Coursey M, et al. Left ventricular function and response to enalapril in patients with Duchenne muscular dystrophy during the second decade of life. Am J Cardiol 2006;98:825-7.

7. Bouhouch R, Elhouari T, Oukerraj L, et al. Management of cardiac involvement in neuromuscular diseases: Review. Open Cardiovasc Med J 2008;2:93-6.

8. Emery AE.The muscular dystrophies. Lancet 2002;359:687-95.

9. Silva MC, Meira ZM, Gurgel Giannetti J, et al. Myocardial delayed enhancement by magnetic resonance imaging in patients with muscular dystrophy. J Am Coll Cardiol 2007;49:1874-9.

10. Yilmaz A, Gdynia HJ, Baccouche H, et al. Cardiac involvement in patients with Becker muscular dystrophy: New diagnostic and pathophysiological insights by a CMR approach. J Cardiovasc Magn Reson 2008;10:50.

11. Hoffman EP, Brown RH Jr, Kunkel LM. Dystrophin: The protein product of the Duchenne muscular dystrophy locus. Cell 1987;51:919-28.

12. Monaco AP, Bertelson CJ, Liechti-Gallati S, Moser H, Kunkel LM. An explanation for the phenotypic differences between patients bearing partial deletions of the DMD locus. Genomics 1988;2:90-5.

13. Bushby K, Finkel R, Birnkrant DJ, et al. Diagnosis and management of Duchenne muscular dystrophy, part 2: Implementation of multidisciplinary care. Lancet Neurol 2010;9:177-89.

14. Rafael JA, Cox GA, Corrado K, Jung D, Campbell KP, Chamberlain JS. Forced expression of dystrophin deletion constructs reveals structure-function correlations. J Cell Biol 1996;134:93-102.

15. Corrado K, Rafael JA, Mills PL, et al. Transgenic mdx mice expressing dystrophin with a deletion in the actin-binding domain display a "mild Becker" phenotype. J Cell Biol 1996;134:873-84.

16. Petrof BJ, Shrager JB, Stedman HH, Kelly AM, Sweeney HL. Dystrophin protects the sarcolemma from stresses developed during muscle contraction. Proc Natl Acad Sci USA 1993;90:3710-4

17. Wallace GQ, McNally EM. Mechanisms of muscle degeneration, regeneration and repair in the muscular dystrophies. Annu Rev Physiol 2009;71:37-57. 
18. Bushby KM, Thambyayah M, Gardner-Medwin D. Prevalence and incidence of Becker muscular dystrophy. Lancet 1991;337:1022-4.

19. Emery AE, Skinner R. Clinical studies in benign (Becker type) X-linked muscular dystrophy. Clin Genet 1976;10:189-201.

20. Bradley WG, Jones MZ, Mussini JM, Fawcett PR. Becker-type muscular dystrophy. Muscle Nerve 1978;1:111-32.

21. Bushby KM, Gardner-Medwin D. The clinical, genetic and dystrophin characteristics of Becker muscular dystrophy. I. Natural history. J Neurol 1993;240:98-104.

22. Hoogerwaard EM, de Voogt WG, Wilde AA, et al. Evolution of cardiac abnormalities in Becker muscular dystrophy over a 13-year period. J Neurol 1997;244:657-63.

23. Towbin JA, Hejtmancik JF, Brink P, et al. X linked dilated cardiomyopathy. Molecular genetic evidence of linkage to the Duchenne muscular dystrophy (dystrophin) gene at the Xp21 locus. Circulation 1993;87:1854-65.

24. van Dijk GP, van der Kooi E, Behin A, et al. High prevalence of incomplete right bundle branch block in facioscapulohumeral muscular dystrophy without cardiac symptoms. Funct Neurol 2014;29:159-65.

25. McNally EM. New approaches in the therapy of cardiomyopathy in muscular dystrophy. Ann Rev Med 2007;58:75-88.

26. Ashwath ML, Jacobs IB, Crowe CA, Ashwath RC, Super DM, Bahler RC. Left ventricular dysfunction in Duchenne muscular dystrophy and genotype. Am J Cardiol 2014;114:284-9.

27. Raman SV, Hor KN, Mazur W, et al. Eplerenone for early cardiomyopathy in Duchenne muscular dystrophy: A randomised, double-blind, placebo-controlled trial. Lancet Neurol 2015;14:153-61.

28. Melacini P, Fanin M, Danieli GA, et al. Myocardial involvement is very frequent among patients affected with subclinical Becker's muscular dystrophy. Circulation 1996;94:3168-75.

29. Politano L, Nigro V, Nigro G, et al. Development of cardiomyopathy in female carriers of Duchenne and Becker muscular dystrophies. JAMA 1996;275:1335-8.

30. Nolan MA, Jones OD, Pedersen RL, Johnston HM. Cardiac assessment in childhood carriers of Duchenne and Becker muscular dystrophies. Neuromuscul Disord 2003;13:129-32.

31. Hoogerwaard EM, Bakker E, Ippel PF, et al. Signs and symptoms of Duchenne muscular dystrophy and Becker muscular dystrophy among carriers in The Netherlands: A cohort study. Lancet 1999;353:2116-9.

32. Hoogerwaard EM, van der Wouw PA, Wilde AA, et al. Cardiac involvement in carriers of Duchenne and Becker muscular dystrophy. Neuromuscul Disord 1999;9:347-51.

33. Grain L, Cortina-Borja M, Forfar C, Hilton-Jones D, Hopkin J, Burch M. Cardiac abnormalities and skeletal muscle weakness in carriers of Duchenne and Becker muscular dystrophies and controls. Neuromuscul Disord 2001;11:186-91.

34. Melacini P, Fanin M, Angelini A, et al. Cardiac transplantation in a Duchenne muscular dystrophy carrier. Neuromuscul Disord 1998;8:585-90.

35. Davies JE, Winokur TS, Aaron MF, Benza RL, Foley BA, Holman WL. Cardiomyopathy in a carrier of Duchenne's muscular dystrophy. J Heart Lung Transplant 2001;20:781-4.

36. Weiss RM, Kerber RE, Jones JK, et al. Exercise-induced left ventricular systolic dysfunction in women heterozygous for dystrophinopathy. J Am Soc Echocardiogr 2010;23:848-53.

37. Mavrogeni S, Bratis K, Papavasiliou A, et al. CMR detects subclinical cardiomyopathy in mother-carriers of Duchenne and Becker muscular dystrophy. JACC Cardiovasc Imaging 2013;6:526-8.

38. Darras BT, Miller DT, Urion DK. Dystrophinopathies. In: Pagon RA, Adam MP, Bird TD, et al, eds. GeneReviews. Seattle: University of Washington, Seattle, 1993-2014.

39. Berko BA, Swift M. X-linked dilated cardiomyopathy. N Engl J Med 1987;316:1186-91.

40. Bione S, Maestrini E, Rivella S, et al. Identification of a novel $\mathrm{X}$-linked gene responsible for Emery-Dreifuss muscular dystrophy. Nat Genet 1994;8:323-7.

41. Manilal S, Nguyen TM, Sewry CA, Morris GE. The EmeryDreifuss muscular dystrophy protein, emerin, is a nuclear membrane protein. Hum Mol Genet 1996;5:801-8.
42. Nagano A, Koga R, Ogawa M, et al. Emerin deficiency at the nuclear membrane in patients with Emery-Dreifuss muscular dystrophy. Nat Genet 1996;12:254-9.

43. Bonne G, Di Barletta MR, Varnous S, et al. Mutations in the gene encoding lamin $\mathrm{A} / \mathrm{C}$ cause autosomal dominant EmeryDreifuss muscular dystrophy. Nat Genet 1999;21:285-8.

44. Raffaele Di Barletta M, Ricci E, et al. Different mutations in the LMNA gene cause autosomal dominant and autosomal recessive Emery-Dreifuss muscular dystrophy. Am J Hum Genet 2000;66:1407-12.

45. Waters DD, Nutter DO, Hopkins LC, Dorney ER. Cardiac features of an unusual X-linked humeroperoneal neuromuscular disease. N Engl J Med 1975;293:1017-22.

46. Voit T, Krogmann O, Lenard HG, et al. Emery-Dreifuss muscular dystrophy: Disease spectrum and differential diagnosis. Neuropediatrics 1988;19:62-71.

47. Bialer MG, McDaniel NL, Kelly TE. Progression of cardiac disease in Emery-Dreifuss muscular dystrophy. Clin Cardiol 1991;14:411-6.

48. FishbeinMC, Siegel RJ, Thompson CE, Hopkins LC. Sudden death of a carrier of $\mathrm{X}$ linked Emery-Dreifuss muscular dystrophy. Ann Intern Med 1993;119:900-5.

49. Merlini L, Granata C, Dominici P, Bonfiglioli S. Emery-Dreifuss muscular dystrophy: Report of five cases in a family and review of the literature. Muscle Nerve 1986;9:481-5.

50. Funakoshi M, Tsuchiya Y, Arahata K. Emerin and cardiomyopathy in Emery-Dreifuss muscular dystrophy. Neuromuscul Disord 1999;9:108-14

51. Boriani G, Gallina M, Merlini L, et al. Clinical relevance of atrial fibrillation/flutter, stroke, pacemaker implant, and heart failure in Emery-Dreifuss muscular dystrophy: A long-term longitudinal study. Stroke 2003;34:901-8.

52. Manilal S, Recan D, Sewry CA, et al. Mutations in Emery-Dreifuss muscular dystrophy and their effects on emerin protein expression. Hum Mol Genet 1998; 7:855-64.

53. Bialer MG, McDaniel NL, Kelly TE. Progression of cardiac disease in Emery-Dreifuss muscular dystrophy. Clin Cardiol 1991;14:411-6.

54. Sakata K, Shimizu M, Ino H, et al. High incidence of sudden cardiac death with conduction disturbances and atrial cardiomyopathy caused by a nonsense mutation in the STA gene. Circulation 2005;111:3352-8.

55. Hauerslev S, Sveen ML, Duno M, Angelini C, Vissing J, Krag TO. Calpain 3 is important for muscle regeneration: Evidence from patients with limb girdle muscular dystrophies. BMC Musculoskelet Disord 2012;13:43.

56. van der Kooi AJ, Barth PG, Busch HF, et al. The clinical spectrum of limb girdle muscular dystrophy. A survey in The Netherlands. Brain 1996;119(Pt 5):1471-80.

57. Laval SH, Bushby KM. Limb-girdle muscular dystrophies - from genetics to molecular pathology. Neuropathol Appl Neurobiol 2004;30:91-105.

58. Messina DN, Speer MC, Pericak-Vance MA, McNally EM. Linkage of familial dilated cardiomyopathy with conduction defect and muscular dystrophy to chromosome 6q23. Am J Hum Genet 1997;61:909-17.

59. Fanin M, Duggan DJ, Mostacciuolo ML, et al. Genetic epidemiology of muscular dystrophies resulting from sarcoglycan gene mutations. J Med Genet 1997;34:973-7.

60. Duggan DJ, Manchester D, Stears KP, Mathews DJ, Hart C, Hoffman EP. Mutations in the delta-sarcoglycan gene are a rare cause of autosomal recessive limb-girdle muscular dystrophy (LGMD2). Neurogenetics 1997;1:49-58.

61. Vainzof M, Passos-Bueno MR, Pavanello RC, Marie SK, Oliveira AS, Zatz M. Sarcoglycanopathies are responsible for $68 \%$ of severe autosomal recessive limb-girdle muscular dystrophy in the Brazilian population. J Neurol Sci 1999;164:44-9.

62. Melacini P, Fanin M, Duggan DJ, et al. Heart involvement in muscular dystrophies due to sarcoglycan gene mutations. Muscle Nerve 1999;22:473-9.

63. Politano L, Nigro V, Passamano L, et al. Evaluation of cardiac and respiratory involvement in sarcoglycanopathies. Neuromuscul Disord 2001;11:178-85.

64. Barresi R, Di Blasi C, Negri T, et al. Disruption of heart sarcoglycan complex and severe cardiomyopathy caused by beta sarcoglycan mutations. J Med Genet 2000;37:102-7. 
65. Fanin M, Melacini P, Boito C, Pegoraro E, Angelini C. LGMD2E patients risk developing dilated cardiomyopathy. Neuromuscul Disord 2003;13:303-9.

66. Bushby K, Muntoni F, Bourke JP. 107th ENMC international workshop: The management of cardiac involvement in muscular dystrophy and myotonic dystrophy. 7th-9th June 2002, Naarden, the Netherlands. Neuromuscul Disord 2003;13:166-72.

67. Brockington M, Yuva Y, Prandini P, et al. Mutations in the fukutinrelated protein gene (FKRP) identify limb girdle muscular dystrophy 2I as a milder allelic variant of congenital muscular dystrophy MDC1C. Hum Mol Genet 2001;10:2851-9.

68. Muntoni F, Torelli S, Brockington M. Muscular dystrophies due to glycosylation defects. Neurotherapeutics 2008;5:627-32.

69. Mercuri E, Brockington M, Straub V, et al. Phenotypic spectrum associated with mutations in the fukutin-related protein gene. Ann Neurol 2003;53:537-42.

70. Poppe M, Bourke J, Eagle M, et al. Cardiac and respiratory failure in limb-girdle muscular dystrophy 2I. Ann Neurol 2004:56:738-41.

71. Boito CA, Melacini P, Vianello A, et al. Clinical and molecular characterization of patients with limb-girdle muscular dystrophy type 2I. Arch Neurol 2005;62:1894-9.

72. Sveen ML, Thune JJ, Kober L, Vissing J. Cardiac involvement in patients with limb-girdle muscular dystrophy type 2 and Becker muscular dystrophy. Arch Neurol 2008;65:1196-201.

73. Wahbi K, Meune C, Hamouda el H, et al. Cardiac assessment of limb-girdle muscular dystrophy 2I patients: An echography, Holter ECG and magnetic resonance imaging study. Neuromuscul Disord 2008;18:650-5.

74. Harper PS. Myotonic dystrophy. London: Saunders; 2001.

75. Harley HG, Rundle SA, MacMillan JC, et al. Size of the unstable CTG repeat sequence in relation to phenotype and parental transmission in myotonic dystrophy. Am J Hum Genet 1993;52:1164-74.

76. Mathieu J, Allard P, Potvin L, Prevost C, Begin P. A 10-year study of mortality in a cohort of patients with myotonic dystrophy. Neurology 1999;52:1658-62.

77. de Die-Smulders CE, Hpweler CJ, Thijs C, et al. Age and causes of death in adult-onset myotonic dystrophy. Brain 1998;121:1557-63.

78. Groh WJ, Groh MR, Saha C, et al. Electrocardiographic abnormalities and sudden death in myotonic dystrophy type 1 . N Engl J Med 2008;358:2688-97.

79. Bassez G, Lazarus A, Desguerre I, et al. Severe cardiac arrhythmias in young patients with myotonic dystrophy type 1 . Neurology 2004;63:1939-41.

80. Phillips MF, Harper PS. Cardiac disease in myotonic dystrophy. Cardiovasc Res 1997;33:13-22.

81. Nguyen HH, Wolfe 3rd JT, Holmes Jr DR, Edwards WD. Pathology of the cardiac conduction system in myotonic dystrophy: A study of 12 cases. J Am Coll Cardiol 1988;11:662-71.

82. De Ambroggi L, Raisaro A, Marchiano V, Radice S, Meola G. Cardiac involvement in patients with myotonic dystrophy: Characteristic features of magnetic resonance imaging. Eur Heart J 1995; 16:1007-10.

83. Bhakta D, Lowe MR, Groh WJ. Prevalence of structural cardiac abnormalities in patients with myotonic dystrophy type I. Am Heart J 2004;147:224-7.

84. Orndahl G, Thulesius O, Enestroem S, Dehlin O. The heart in myotonic disease. Acta Med Scand 1964;176:479-91.

85. Hermans MC, Faber CG, Pinto YM. Sudden death in myotonic dystrophy. N Engl J Med 2008;359:1626-8.

86. Bachinski LL, Czernuszewicz T, Ramagli LS, et al. Premutation allele pool in myotonic dystrophy type 2. Neurology 2009;72:490-7.

87. Day JW, Ricker K, Jacobsen JF, et al. Myotonic dystrophy type: Molecular, diagnostic and clinical spectrum. Neurology 2003;60:657-64.

88. Goldfarb LG, Dalakas MC. Tragedy in a heartbeat: Malfunctioning desmin causes skeletal and cardiac muscle disease. J Clin Invest 2009;119:1806-13.

89. Vicart P, Caron A, Guicheney P, et al. A missense mutation in the alphaB-crystallin chaperone gene causes a desmin-related myopathy. Nat Genet 1998;20:92-5.
90. Selcen D, Engel AG. Myofibrillar myopathy caused by novel dominant negative alpha B-crystallin mutations. Ann Neurol 2003;54:804-10.

91. Selcen D, Muntoni F, Burton BK, et al. Mutation in BAG3 causes severe dominant childhood muscular dystrophy. Ann Neurol 2009;65:83-9.

92. Griggs R, Vihola A, Hackman P, et al. Zaspopathy in a large classic late-onset distal myopathy family. Brain 2007;130:1477-84.

93. Nishino I, Fu J, Tanji K, et al. Primary LAMP-2 deficiency causes X-linked vacuolar cardiomyopathy and myopathy (Danon disease). Nature 2000;406:906-10.

94. Sugie K, Yamamoto A, Murayama K, et al. Clinicopathological features of genetically confirmed Danon disease. Neurology 2002;58:1773-8.

95. Spencer CT, Bryant RM, Day J, et al. Cardiac and clinical phenotype in Barth syndrome. Pediatrics 2006;118:e337-46.

96. Danek A, Rubio JP, Rampoldi L, et al. McLeod neuroacanthocytosis: Genotype and phenotype. Ann Neurol 2001;50:755-64.

97. Windpassinger C, Schoser B, Straub V, et al. An X-linked myopathy with postural muscle atrophy and generalized hypertrophy, termed XMPMA, is caused by mutations in FHL1. Am J Hum Genet 2008;82:88-99.

98. Schessl J, Taratuto AL, Sewry C, et al. Clinical, histological and genetic characterization of reducing body myopathy caused by mutations in FHL1. Brain 2009;132:452-64.

99. Carmignac V, Salih MA, Quijano-Roy S, et al. C-terminal titin deletions cause a novel early-onset myopathy with fatal cardiomyopathy. Ann Neurol 2007;61:340-51.

100. Overeem S, Schelhaas HJ, Blijham PJ, et al. Symptomatic distal myopathy with cardiomyopathy due to a MYH7 mutation. Neuromuscul Disord 2007;17:490-3.

101. Uro-Coste E, Arne-Bes MC, Pellissier JF, et al. Striking phenotypic variability in two familial cases of myosin storage myopathy with a MYH7 Leu1793pro mutation. Neuromuscul Disord 2009;19:163-6.

102. Santos MA, Costa Fde A, Travessa AF, et al. Duchenne muscular dystrophy: Electrocardiographic analysis of 131 patients. Arq Bras Cardiol 2010;94:620-4.

103. Canaveris G, Halpern MS. Intraventricular conduction disturbances in flying personnel: Incomplete right bundle branch block. Aviat Space Environ Med 1988;59:960-4.

104. Eriksson P, Hansson Po, Eriksson H, et al. Bundle-branch block in a general male population: The study of men born 1913. Circulation 1998;98:2494-500.

105. Sanna T, Dello Russo A, Toniolo D, et al. Cardiac features of Emery-Dreifuss muscular dystrophy caused by lamin A/C gene mutations. Eur Heart J 2003;24:2227-36.

106. Fishbein MC, Siegel RJ, Thompson CE, Hopkins LC. Sudden death of a carrier of X-linked Emery-Dreifuss muscular dystrophy. Ann Intern Med 1993;119:900-5.

107. Fatkin D, MacRae C, Sasaki T, et al. Missense mutations in the rod domain of the lamin A/C gene as causes of dilated cardiomyopathy and conduction-system disease. N Engl J Med 1999;341:1715-24.

108. Gomes L, Pereira T, Martins L. Cardiovascular profile in myotonic dystrophy type 1 : Analysis of a case series in a specialized center. Rev Port Cardiol 2014;33:765-72.

109. Kaspar RW, Allen HD, Montanaro F. Current understanding and management of dilated cardiomyopathy in Duchenne and Becker muscular dystrophy. J Am Acad Nurse Pract 2009;21:241-9.

110. Merlevede K, Vermander D, Theys P, Legius E, Ector H, Robberecht W. Cardiac involvement and CTG expansion in myotonic dystrophy. J Neurol 2002;249:693-8.

111. Sá MI, Cabral S, Costa PD, Coelho T, Freitas M, Gomes JL. Ambulatory electrocardiographic monitoring in type 1 myotonic dystrophy. Rev Port Cardiol 2007;26:745-53.

112. Brembilla-Perrot B, Schwartz J, Huttin O, et al. Atrial flutter or fibrillation is the most frequent and life-threatening arrhythmia in myotonic dystrophy. Pacing Clin Electrophysiol 2014;37:329-35.

113. Petri H, Witting N, Ersbøll MK, et al. High prevalence of cardiac involvement in patients with myotonic dystrophy type 1: A cross-sectional study. Int J Cardiol 2014;174:31-6. 
114. Sansone VA, Brigonzi E, Schoser B, et al. The frequency and severity of cardiac involvement in myotonic dystrophy type 2 (DM2): Long-term outcomes. Int J Cardiol 2013;168:1147-53.

115. Rhodes J, Margossian R, Darras BT, et al. Safety and efficacy of carvedilol therapy for patients with dilated cardiomyopathy secondary to muscular dystrophy. Pediatr Cardiol 2008;29:343-51.

116. Sanna T, Dello Russo A, Toniolo D, et al. Cardiac features of Emery-Dreifuss muscular dystrophy caused by lamin A/C gene mutations. Eur Heart J 2003;24:2227-36.

117. Viollet L, Thrush PT, Flanigan KM, Mendell JR, Allen HD. Effects of angiotensin-converting enzyme inhibitors and/or beta blockers on the cardiomyopathy in Duchenne muscular dystrophy. Am J Cardiol 2012;110:98-102.

118. English KM, Gibbs JL. Cardiac monitoring and treatment for children and adolescents with neuromuscular disorders. Dev Med Child Neurol 2006;48:231-5.

119. Ashwath ML, Jacobs IB, Crowe CA, Ashwath RC, Super DM, Bahler RC. Left ventricular dysfunction in Duchenne muscular dystrophy and genotype. Am J Cardiol 2014;114:284-9.

120. Schade van Westrum SM, Dekker LR, et al. Cardiac involvement in Dutch patients with sarcoglycanopathy: A cross-sectional cohort and follow-up study. Muscle Nerve 2014:50:909-13.

121. Fayssoil A, Nardi O, Orlikowski D, Annane D. Cardiac asynchrony in Duchenne muscular dystrophy. J Clin Monit Comput 2013;27:587-9.

122. Draminska A, Kuch-Wocial A, Szulc M, et al. Echocardiographic assessment of left ventricular morphology and function in patients with Emery-Dreifuss muscular dystrophy. Int J Cardiol 2005;102:207-10.

123. Sveen ML, Thune JJ, Køber L, Vissing J. Cardiac involvement in patients with limb-girdle muscular dystrophy type 2 and Becker muscular dystrophy. Arch Neurol 2008;65:1196-201.

124. Poppe M, Bourke J, Eagle M, et al. Cardiac and respiratory failure in limb-girdle muscular dystrophy 2I. Ann Neurol 2004;56:738-41.

125. Bhakta D, Lowe MR, Groh WJ. Prevalence of structural cardiac abnormalities in patients with myotonic dystrophy type I. Am Heart J 2004;147:224-227.

126. Fayssoil A, Nardi O, Annane D, Orlikowski D. Diastolic Function in Steinert's Disease. Neurol Int 2014;6:5140.

127. Tsuburaya RS, Uchizumi H, Ueda M, et al. Utility of real-time three-dimensional echocardiography for Duchenne muscular dystrophy with echocardiographic limitations. Neuromuscul Disord 2014;24:402-8.

128. Ballo P, Giaccardi M, Colella A, et al. Mechanical and electrophysiological substrate for recurrent atrial flutter detected by right atrial speckle tracking echocardiography and electroanatomic mapping in myotonic dystrophy type 1 . Circulation 2013;127:1422-4.

129. Sansone VA, Brigonzi E, Schoser B, et al. The frequency and severity of cardiac involvement in myotonic dystrophy type 2 (DM2): Long-term outcomes. Int J Cardiol 2013;168:1147-53.

130. Yamamoto T, Tanaka H, Matsumoto K, et al. Utility of transmural myocardial strain profile for prediction of early left ventricular dysfunction in patients with Duchenne muscular dystrophy. Am J Cardiol 2013;111:902-7.

131. Mori K, Hayabuchi Y, Inoue M, et al. Myocardial strain imaging for early detection of cardiac involvement in patients with Duchenne's progressive muscular dystrophy. Echocardiography 2007;24:598-608.

132. Schalla S, Nagel E, Lehmkuhl H, et al. Comparison of magnetic resonance real-time imaging of LV function with conventional magnetic resonance imaging and echocardiography. Am J Cardiol 2001;87:95-9.

133. Ashford MW, Liu W, Lin SJ, et al. Occult cardiac contractile dysfunction in dystrophin-deficient children revealed by cardiac magnetic resonance strain imaging. Circulation 2005;112:2462-7.

134. Hor KN, Wansapura J, Markham LW, et al. Circumferential strain analysis identifies strata of cardiomyopathy in Duchenne muscular dystrophy: A cardiac magnetic resonance tagging study. J Am Coll Cardiol 2009;53:1204-10.

135. Hagenbuch SC, Gottliebson WM, Wansapura J, et al. Detection of progressive cardiac dysfunction by serial evaluation of circumferential strain in patients with Duchenne muscular dystrophy. Am J Cardiol 2010;105:1451-5.

136. Mavrogeni S, Papavasiliou A, Skouteli E, Magoutas A, Dangas G. Cardiovascular magnetic resonance imaging evaluation of two families with Becker muscular dystrophy. Neuromuscul Disord 2010;20:717-9.

137. Duboc D, Meune C, Lerebours G, Devaux JY, Vaksmann G, Becane HM. Effect of perindopril on the onset and progression of left ventricular dysfunction in Duchenne muscular dystrophy. J Am Coll Cardiol 2005;45:855-7.

138. Silva MC, Meira ZM, Gurgel Giannetti J, et al. Myocardial delayed enhancement by magnetic resonance imaging in patients with muscular dystrophy. J Am Coll Cardiol 2007;49:1874-9.

139. Menon SC, Etheridge SP, Liesemer KN, et al. Predictive value of myocardial delayed enhancement in Duchenne muscular dystrophy. Pediatr Cardiol 2014;35:1279-85.

140. Turkbey EB, Gai N, Lima JA, et al. Assessment of cardiac involvement in myotonic muscular dystrophy by T1 mapping on magnetic resonance imaging. Heart Rhythm 2012;9:1691-7.

141. Smith GC, Kinali M, Prasad SK, et al. Primary myocardial dysfunction in autosomal dominant EDMD. A tissue doppler and cardiovascular magnetic resonance study. J Cardiovasc Magn Reson 2006;8:723-30.

142. Yilmaz A, Gdynia HJ, Mahrholdt H, Sechtem U. Cardiovascular magnetic resonance reveals similar damage to the heart of patients with Becker and limb-girdle muscular dystrophy but no cardiac symptoms. J Magn Reson Imaging 2009;30:876-7.

143. Rosales XQ, Moser SJ, Tran T, et al. Cardiovascular magnetic resonance of cardiomyopathy in limb girdle muscular dystrophy 2B and 2I. J Cardiovasc Magn Reson 2011;13:39.

144. Wahbi K, Meune C, Hamouda el H, et al. Cardiac assessment of limb-girdle muscular dystrophy 2I patients: An echography, Holter ECG and magnetic resonance imaging study. Neuromuscul Disord 2008;18:650-5.

145. Gaul C, Deschauer M, Tempelmann C, et al. Cardiac involvement in limb-girdle muscular dystrophy 2I: Conventional cardiac diagnostic and cardiovascular magnetic resonance. J Neurol 2006;253:1317-22.

146. Hermans MC, Faber CG, Bekkers SC, et al. Structural and functional cardiac changes in myotonic dystrophy type 1: A cardiovascular magnetic resonance study. J Cardiovasc Magn Reson 2012;14:48.

147. Finsterer J, Stolberger C, Kopsa W. Noncompaction in myotonic dystrophy type 1 on cardiac MRI. Cardiology 2005;103:167-8.

148. Wahbi K, Meune C, Bassez G, et al. Left ventricular noncompaction in a patient with myotonic dystrophy type 2 . Neuromuscul Disord 2008;18:331-3.

149. Kim RJ, Fieno DS, Parrish TB, et al. Relationship of MRI delayed contrast enhancement to irreversible injury, infarct age, and contractile function. Circulation 1999;100:1992-2002.

150. Kwong RY, Chan AK, Brown KA, et al. Impact of unrecognized myocardial scar detected by cardiac magnetic resonance imaging on event-free survival in patients presenting with signs or symptoms of coronary artery disease. Circulation 2006;113:2733-43.

151. Perazzolo Marra M, De Lazzari M, Zorzi A, et al. Impact of the presence and amount of myocardial fibrosis by cardiac magnetic resonance on arrhythmic outcome and sudden cardiac death in nonischemic dilated cardiomyopathy. Heart Rhythm 2014;11:856-63.

152. Badorff C, Knowlton KU. Dystrophin disruption in enterovirusinduced myocarditis and dilated cardiomyopathy: From bench to bedside. Med Microbiol Immunol 2004;193:121-6.

153. Mavrogeni S, Papavasiliou A, Spargias K, et al. Myocardial inflammation in Duchenne Muscular Dystrophy as a precipitating factor for heart failure: A prospective study. BMC Neurol 2010;10:33.

154. Dennert R, Crijns HJ, Heymans S. Acute viral myocarditis. Eur Heart J 2008;29:2073-82.

155. Cooper LT, Baughman KL, Feldman AM, et al. American Heart Association, American College of Cardiology, European Society of Cardiology, Heart Failure Society of America, Heart Failure Association of the European Society of Cardiology. 
The role of endomyocardial biopsy in the management of cardiovascular disease: A scientific statement from the American Heart Association, the American College of Cardiology, and the European Society of Cardiology. Endorsed by the Heart Failure Society of America and the Heart Failure Association of the European Society of Cardiology. J Am Coll Cardiol 2007:50:1914-31.

156. Friedrich MG, Sechtem U, Schulz-Menger J, et al; International Consensus Group on Cardiovascular Magnetic Resonance in Myocarditis. Cardiovascular magnetic resonance in myocarditis: A JACC White Paper. J Am Coll Cardiol 2009;53:1475-87.
157. Bertaso AG, Bertol D, Duncan BB, Foppa M. Epicardial fat: Definition, measurements and systematic review of main outcomes. Arq Bras Cardiol 2013;101:e18-e28.

158. Frankel KA, Rosser RJ. The pathology of the heart in progressive muscular dystrophy: Epimyocardial fibrosis. Hum Pathol 1976;7:375-86.

159. Florian A, Ludwig A, Rösch S, Yildiz H, Sechtem U, Yilmaz A. Myocardial fibrosis imaging based on T1-mapping and extracellular volume fraction (ECV) measurement in muscular dystrophy patients: Diagnostic value compared with conventional late gadolinium enhancement (LGE) imaging. Eur Heart J Cardiovasc Imaging 2014;15:1004-12. 